\title{
Characterization and kinetics study of the photochlorination of polyethylene
}

\begin{abstract}
Ali Moradi ${ }^{1}$, Ahmad Ramazani Saadat Abadi $^{2}$ and Mohammad Shahrokhi ${ }^{2}$
The radical chlorination of polyethylene was carried out in perchloroethylene solvent using chlorine gas and ultraviolet photoradiation to investigate a reaction kinetics model. The recurrent structure of chloromethylene (-CHCl-) and methylene $\left(-\mathrm{CH}_{2}-\right)$ groups and the percentage of substituted chlorine were determined using hydrogen-nuclear magnetic resonance (H-NMR) $(500 \mathrm{MHz})$ spectra. A kinetics model has been proposed for this reaction in which the conversion of methylene $\left(-\mathrm{CH}_{2}-\right)$ units to chloromethylene (-CHCl-) units was considered to be the main reaction step. The simplified version of the obtained kinetics model indicates that the reaction is first order with respect to the chlorine gas concentration and zero order with respect to the methylene concentration up to $40 \%$ chlorination. At the first stage of the reaction, the concentration of $\gamma$-methylene sequences is high. Once the degree of chlorination exceeds $40 \%$, the reaction order changes and becomes zero order with respect to the chlorine gas concentration and first order with respect to the methylene group concentration. At this stage of the reaction, the concentration of $\gamma$-methylene groups has decreased considerably.
\end{abstract}

Polymer Journal (2012) 44, 973-977; doi:10.1038/pj.2012.42; published online 18 April 2012

Keywords: chloromethylene; kinetics model; methylene sequences; polyethylene chlorination

\section{INTRODUCTION}

Chlorinated polyethylene (CPE) has many applications due to its intrinsic properties, including weathering, chemical resistance and ability to modify impact. CPE can be found in several industrial grades, with 10 to $70 \%$ substituted chlorine. ${ }^{1-3}$ By increasing the number of substituted chlorine atoms on the polymer backbone, the crystallinity gradually decreases, and CPE is converted into a soft and flexible thermoplastic. Above $10 \%$ chlorination the flexibility of CPE becomes noticeable, and at $35-40 \%$ chlorination it is in its most flexible form. Above 55\% chlorination the hardness and toughness of the polymer increase considerably. ${ }^{1-4}$

There are two main types of chlorination processes, namely, solution-phase and suspension-phase chlorination. In solution-phase systems, the chlorine atoms are homogenously substituted through the backbone of the polymer, and the obtained CPE does not usually have crystalline blocks, which could be more favorable for rubber applications. Most industrial units produce various types of CPEs in solution-phase systems using a single solvent, such as $\mathrm{CCl}_{4}$, or a mixture of solvents. ${ }^{1-11}$ In the suspension-phase technique, the chlorination reaction is carried out primarily on the surface of polyethylene granules, and the structure of the product is nonuniform or heterogeneous. Both of these methods are usually carried out under a moderate pressure, approximately 5 bar. $^{1-3,12,13}$

Although the kinetics study of the radical chlorination of polyethylene is required for process design purposes and product quality control, this subject has not received considerable attention in the literature. Recently, the quantitative analysis of the radical chlorination reaction of polyethylene for determination of the chlorine percentage and the concentration of methylene sequences during the chlorination reaction was performed by Moradi et al. using hydrogen-nuclear magnetic resonance (H-NMR) $500 \mathrm{MHz}$ spectra and the flask combustion method (IP-244). ${ }^{14-17}$ However, the reaction kinetics of chlorination has not been considered in the above-mentioned works and will be considered in this paper. The concentrations of $\mathrm{CHCl}$ and $\mathrm{CH}_{2}$ groups that are needed to obtain the reaction equations are calculated from H-NMR spectra during the reaction. To obtain the kinetics model, a pattern similar to the one that has been proposed for the chlorination reaction of lowmolecular-weight paraffins has been used.

The radical chlorination of low-molecular-weight paraffins such as n-dodecane and tetrachloroethene has been studied by several researchers. ${ }^{18-22}$ In the photochlorination of tetrachloroethene, the conversion of methylene units $\left(-\mathrm{CH}_{2}-\right)$ to chloromethylene $(-\mathrm{CHCl}-)$ groups has been considered the main reaction. ${ }^{21,22}$ In the radical chlorination of polyethylene, the chlorine atoms are progressively substituted on the polyethylene backbone, which makes the kinetics study of the reaction a difficult task. It seems that the rate of the chlorination reaction strongly depends on the distribution of chlorine atoms along the polymer chain. A kinetics model similar to the chlorination kinetics model of low-molecular-weight alkanes can be

${ }^{1}$ Department of Chemical Engineering, Shahid Bahonar University of Kerman, Kerman, Iran and ${ }^{2}$ Department of Chemical and Petroleum Engineering, Sharif University of Technology, Tehran, Iran

Correspondence: Dr A Moradi, Department of Chemical Engineering, Shahid Bahonar University of Kerman, Jomhoori Islami BLVD, Kerman 76175-133, Iran. E-mail: moradi@mail.uk.ac.ir

Received 11 November 2011; revised 16 January 2012; accepted 17 January 2012; published online 18 April 2012 
considered for the conversion of methylene $\left(-\mathrm{CH}_{2}-\right)$ units to chloromethylene (-CHCl-) groups for modeling the chlorination reactions of polyethylene (PE) to $\mathrm{CPE}$. The overall kinetics reaction may be obtained by considering all of the intermediate radical reactions, including initiation, propagation and termination reactions. In this study, such a kinetics model has been proposed and its validity has been confirmed through experimental study.

\section{Reaction scheme}

The overall reaction equation for the radical chlorination of polyethylene is given below: ${ }^{1}$

$$
-\mathrm{CH}_{2} \mathrm{CH}_{2} \mathrm{CH}_{2} \mathrm{CH}_{2}-+\mathrm{Cl}_{2} \stackrel{h v}{\longrightarrow}-\mathrm{CH}_{2} \underset{\mathrm{Cl}}{\mathrm{C}} \mathrm{HCH}_{2} \mathrm{CH}_{2}-+\mathrm{HCl}
$$

The different steps involved in the radical chlorination of polyethylene can be written as:

(1) Initiation:

$$
\mathrm{Cl}_{2} \stackrel{u v}{\longrightarrow} 2 \stackrel{*}{\mathrm{Cl}}
$$

(2) Propagation:

$$
\begin{gathered}
-\mathrm{CH}_{2} \mathrm{CH}_{2} \mathrm{CH}_{2} \mathrm{CH}_{2} \mathrm{CH}_{2}-+\stackrel{*}{\mathrm{Cl}} \\
\longrightarrow-\mathrm{CH}_{2} \mathrm{CH}_{2} \stackrel{*}{\mathrm{C}} \mathrm{HCH}_{2} \mathrm{CH}_{2}-+\mathrm{HCl} \\
-\mathrm{CH}_{2} \mathrm{CH}_{2} \stackrel{*}{\mathrm{C}} \mathrm{HCH}_{2} \mathrm{CH}_{2} \mathrm{CH}_{2}-+\mathrm{Cl}_{2} \\
\longrightarrow-\mathrm{CH}_{2} \mathrm{CH}_{2} \underset{\mathrm{Cl}}{\mathrm{C}} \mathrm{HCH}_{2} \mathrm{CH}_{2}-+\stackrel{*}{\mathrm{Cl}}
\end{gathered}
$$

(3) Termination:

$$
\begin{aligned}
& -\mathrm{CH}_{2} \mathrm{CH}_{2} \stackrel{*}{\mathrm{CH}} \mathrm{CH}_{2} \mathrm{CH}_{2}-+-\mathrm{CH}_{2} \mathrm{CH}_{2} \stackrel{*}{\mathrm{CH}} \mathrm{CH}_{2} \mathrm{CH}_{2}- \\
& \longrightarrow \begin{array}{l}
-\mathrm{CH}_{2} \mathrm{CH}_{2} \mathrm{CHCH}_{2} \mathrm{CH}_{2}- \\
-\mathrm{CH}_{2} \mathrm{CH}_{2} \mathrm{CHCH}_{2} \mathrm{CH}_{2}-
\end{array}
\end{aligned}
$$

$$
\begin{aligned}
& \stackrel{\mathrm{CH}_{2} \mathrm{CH}_{2}}{\longrightarrow} \stackrel{*}{\mathrm{C}} \mathrm{HCH}_{2} \mathrm{CH}_{2}-+\stackrel{*}{\mathrm{CH}_{2}} \underset{C_{\mathrm{Cl}}}{\mathrm{C}} \mathrm{HCH}_{2} \mathrm{CH}_{2}- \\
& \stackrel{*}{\mathrm{Cl}}+\stackrel{*}{\mathrm{Cl}} \longrightarrow \mathrm{Cl}_{2}
\end{aligned}
$$

When the chlorine content is high, polymer chains can have several chloromethylene groups with different sequence structures. Therefore, the above mechanism can be complicated when the chlorine content is high because of the hindrance effects of the chlorine groups.

\section{The proposed kinetics model for the radical chlorination of polyethylene}

In this attempt to obtain a kinetics model for the radical chlorination of polyethylene, the methylene $\left(-\mathrm{CH}_{2}-\right)$ and chloromethylene $(-\mathrm{CHCl}-)$ groups are considered to be individual reactive sites and product units, respectively. The proposed mechanism was inspired by the photochlorination reaction of tetrachloroethene. ${ }^{21,22}$ Hence, the results of lowmolecular-weight reactions are used to model the radical chlorination of polyethylene as follows. (a) Initiation:

$$
\mathrm{Cl}_{2} \stackrel{h v}{\longrightarrow} 2 \mathrm{Cl}^{*},-r_{1}=\phi I
$$

(b) Propagation:

$$
\begin{aligned}
& -\mathrm{CH}_{2}-+\mathrm{Cl}^{*} \longrightarrow-\mathrm{CH}^{*}-+\mathrm{HCl},-r_{2}=K_{2} B X \\
& -\mathrm{CH}^{*}-+\mathrm{Cl}_{2} \longrightarrow-\mathrm{CHCl}-+\mathrm{Cl}^{*},-r_{3}=K_{3} A Y
\end{aligned}
$$

(c) Termination:

$$
\begin{aligned}
& -\mathrm{CH}^{*}-+-\mathrm{CH}^{*}-\longrightarrow-\mathrm{CH}_{2} \mathrm{CH}_{2}-,-r_{4}=K_{4} Y^{2} \\
& -\mathrm{CH}^{*}-+\mathrm{Cl}^{*} \longrightarrow-\mathrm{CHCl}-,-r_{5}=K_{5} X Y \\
& \mathrm{Cl}^{*}+\mathrm{Cl}^{*} \longrightarrow \mathrm{Cl}_{2},-r_{6}=K_{6} X^{2}
\end{aligned}
$$

where $A, B, X, Y, \varphi$ and $I$ denote the concentrations of chlorine, methylene, chlorine radicals and methylene radicals, the intensity of ultraviolet light, and its quantum yield, respectively.

Using the pseudo-steady-state approximation, the following equations are obtained:

$$
\begin{aligned}
& -\mathrm{d} X / \mathrm{d} t=2 r_{1}-r_{2}+r_{3}-r_{5}-2 r_{6}=0 \\
& -\mathrm{d} Y / \mathrm{d} t=r_{2}-r_{3}-2 r_{4}-r_{5}=0 \\
& r=r_{3}=-\mathrm{d} A / \mathrm{d} t=-\mathrm{d} B / \mathrm{d} t=\mathrm{d} C / \mathrm{d} t
\end{aligned}
$$

where $C$ shows the concentration of chloromethylene groups.

Using the above equations, the concentration of methylene radicals and the rate of reaction can be obtained as:

$$
\begin{aligned}
& Y=\left(\varphi I / K_{4}\right)^{0.5}\left[1+\frac{K_{5}\left(K_{3} A\right)}{K_{4}\left(K_{2} B\right)}+\frac{K_{6}\left(K_{3} A\right)^{2}}{K_{4}\left(K_{2} B\right)^{2}}\right]^{-0.5} \\
& r=r_{3}=K_{3} A Y=K_{3}\left(\varphi I / K_{4}\right)^{0.5} A\left[1+\frac{K_{5}\left(K_{3} A\right)}{K_{4}\left(K_{2} B\right)}+\frac{K_{6}\left(K_{3} A\right)^{2}}{K_{4}\left(K_{2} B\right)^{2}}\right]^{-0.5}
\end{aligned}
$$

Depending on the importance of the termination steps, equation (18) can be simplified in three different ways. If the effects of termination rates (12) and (13), or $K_{5}$ and $K_{6}$ are negligible, equation (18) is reduced to:

$$
r=K_{3}\left(\varphi I / K_{4}\right)^{0.5} A
$$

This means that the reaction is first order with respect to the chlorine concentration and zero order with respect to the concentration of methylene groups.

If termination is dominated by the mechanism presented by equation (13) or if $K_{4}$ and $K_{5}$ are negligible, then equation (18) can be written as:

$$
r=K_{3}\left(\varphi I / K_{4}\right)^{0.5} A\left[\frac{K_{6}\left(K_{3} A\right)^{2}}{K_{4}\left(K_{2} B\right)^{2}}\right]^{-0.5}=\frac{K_{2}}{K_{6}^{0.5}}(\varphi I)^{0.5} B
$$

This means that the reaction is zero order with respect to the chlorine concentration and first order with respect to the methylene group concentration.

Finally, if termination is dominated by equation (12) or $K_{4}$ and $K_{6}$ are negligible, equation (18) reduces to:

$$
r=K_{3}\left(\varphi I / K_{4}\right)^{0.5} A\left[\frac{K_{5}\left(K_{3} A\right)}{K_{4}\left(K_{2} B\right)}\right]^{-0.5}=\left[\frac{K_{3} K_{2}}{K_{5}}\right]^{0.5}(\varphi I)^{0.5}[A B]^{0.5} .
$$

This means that the reaction is half order with respect to the chlorine and methylene group concentrations. ${ }^{21,22}$

However, the experimental data can be used to help identify which of the above-mentioned reaction rates is valid. 


\section{MATERIALS AND METHODS}

\section{Material and equipment}

Industrial grades of perchloroethylene and methanol after double distillation were used as the solvent and antisolvent, respectively. The pure powder of high density polyethylene (HDPE) was obtained from an Iranian petrochemical company (Arak, Iran). Industrial chlorine gas with a purity of $99.5 \%$ was used as the chlorine source. The deuterated benzene and chloroform used in the NMR analysis technique were prepared by the Merck Chemical Company (Merck, Darmstadt, Germany).

The experimental setup consisted of a 2-1 Pyrex reactor (Goldis Company, Tehran, Iran), a condenser, a chlorine gas cylinder, the ultraviolet cell and a rotameter for measuring the chlorine volume flow rate. A neutralization system was applied to the exhaust gas. The H-NMR $500 \mathrm{MHz}$ apparatus, Bruken Drx-500 Avance model (Bruken Company, Rheinstetten, Germany) with a 5-mm QNP probe and an internal reference of tetramethylsilane) was used to analyze the experimental results.

\section{Experiment}

CPE can be produced by several methods, such as bulk, solution or suspension polymerization. To obtain a homogeneous CPE product, the solution-phase system was selected. ${ }^{1}$

In this research, using chlorine gas and ultraviolet light, several preliminary reactions were carried out in the solution phase (that is, using perchloroethylene as the solvent) to achieve stable and suitable conditions for the chlorination reaction. Using different analytical tests, it was recognized that a temperature of $100^{\circ} \mathrm{C}, 1$ bar pressure and a rate of 0.41 per min of chlorine gas are appropriate conditions to produce different degrees of CPE. Samples were taken every $50 \mathrm{~min}$, and the reaction time was set to $6 \mathrm{~h}$. The schematic diagram of the laboratory setup is shown in Figure 1.

The H-NMR ( $500 \mathrm{MHZ}$ ) spectra were taken in deuterated benzene at $80^{\circ} \mathrm{C}$.

\section{RESULTS AND DISCUSSION}

In this section, the H-NMR spectra are first interpreted, and then the percentage of chlorination was calculated from these spectra during the course of the reaction. Next, the concentrations of methylene and chloromethylene sequences in the vicinity of the substituted chlorine were determined. Finally, the obtained kinetics equations were evaluated by the H-NMR data, and the appropriate kinetics model was selected.

\section{Interpretation of the H-NMR spectra}

The chlorination reaction was conducted under the operation conditions given in the section Experiment. During the reaction, samples were taken and analyzed by the H-NMR technique. As an example, one of these spectra is given in Figure 2. ${ }^{15}$

As can be seen in Figure 2, the group of peaks appearing at approximately 3.6-4.7 p.p.m. (parts per million), at 1-2.5 p.p.m. and under 1 p.p.m. show the resonance of chloromethylene protons $(-\mathrm{CHCl}-)$, methylene protons $\left(-\mathrm{CH}_{2}-\right)$ and methyl $\left(-\mathrm{CH}_{3}-\right)$ groups, respectively. ${ }^{23-25}$ The chlorination percentage can be obtained from these spectra as explained below.

Let the summation of the integration values of methyl, methylene and chloromethylene protons be denoted as $S_{1}, S_{2}$ and $S_{3}$, respectively. As the number of hydrogen atoms is three times larger than the number of carbon atoms in the methyl group, the number of hydrogen atoms is twice the number of carbon atoms in the methylene group, and the numbers of chlorine, carbon and hydrogen atoms are equal in the chloromethylene group, the chlorine percentage can be calculated as follows:

Chlorine percentage

$$
=\left(M_{\mathrm{Cl}} \times S_{3}\right) /\left[S_{3} \times M_{\mathrm{CHCl}}+\left(S_{2} / 2\right) \times M_{\mathrm{CH}_{2}}+\left(S_{1} / 3\right) \times M_{\mathrm{CH}_{3}}\right]
$$

where $M_{\mathrm{Cl}}, M_{\mathrm{CHCl}}, \mathrm{M}_{\mathrm{CH} 3}$ and $\mathrm{M}_{\mathrm{CH} 2}$ indicate the formula weights of $\mathrm{Cl}, \mathrm{CHCl}, \mathrm{CH}_{3}$ and $\mathrm{CH}_{2}$, respectively.

As the sum of methylene and chloromethylene concentrations should be equal to the initial value of the methylene concentration, the concentration of chloromethylene can be calculated from the following relation:

$$
\begin{aligned}
{[\mathrm{CHCl}]=\left[\mathrm{CH}_{2}\right]_{0}-\left[\mathrm{CH}_{2}\right],\left[\mathrm{CH}_{2}\right]_{0} } & =m / M_{\mathrm{CH}_{2}}=4.29, \\
m & =60 \mathrm{~g}, M_{\mathrm{CH}_{2}}=14
\end{aligned}
$$

where $\left[\mathrm{CH}_{2}\right]_{0}$ and $[\mathrm{CHCl}]$ denote the initial concentrations of methylene and chloromethylene, respectively.

The experimental results for different runs are given in Table 1. The accuracy of the results obtained by this method has been checked via the flask combustion method. ${ }^{15}$

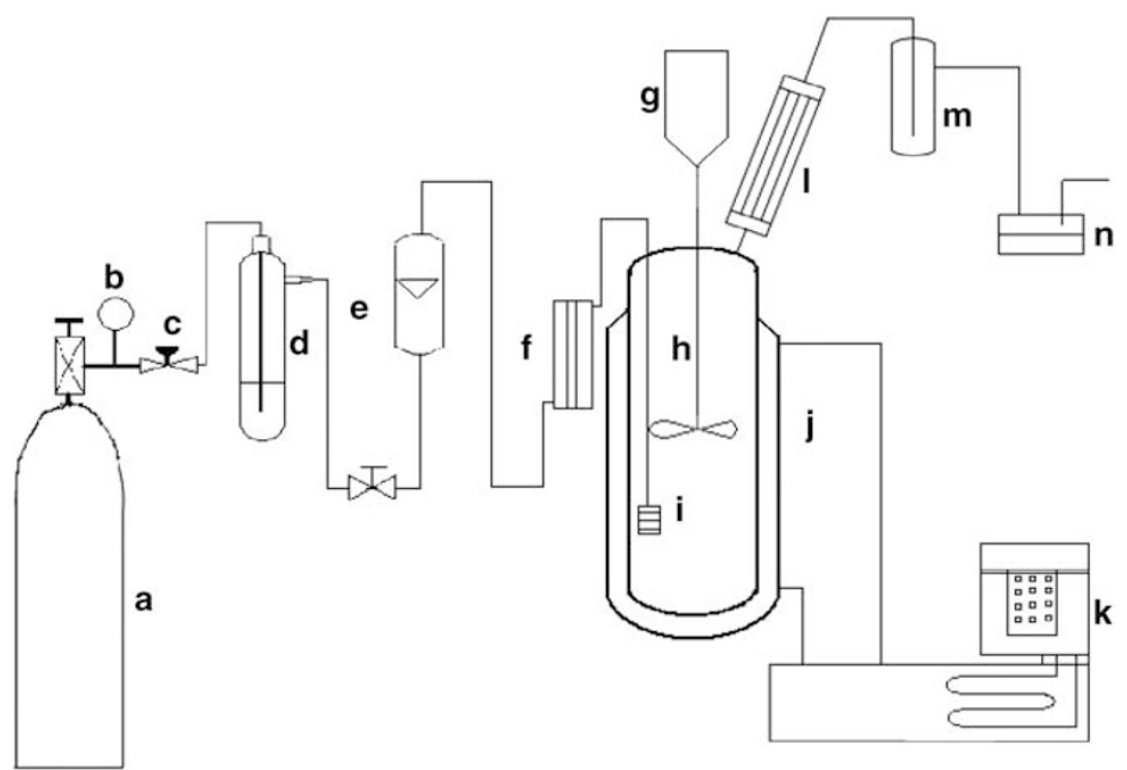

Figure 1 Schematic of the reaction setup: (a) chlorine gas cylinder, (b) pressure gage, (c) needle valve, (d) gas trap, (e) flow meter, (f) ultraviolet light, (g) mechanical mixer, (h) impeller, (i) gas disperser, (j) reactor, (k) oil bath, (I) condenser, (m) trap and (n) neutralization. 


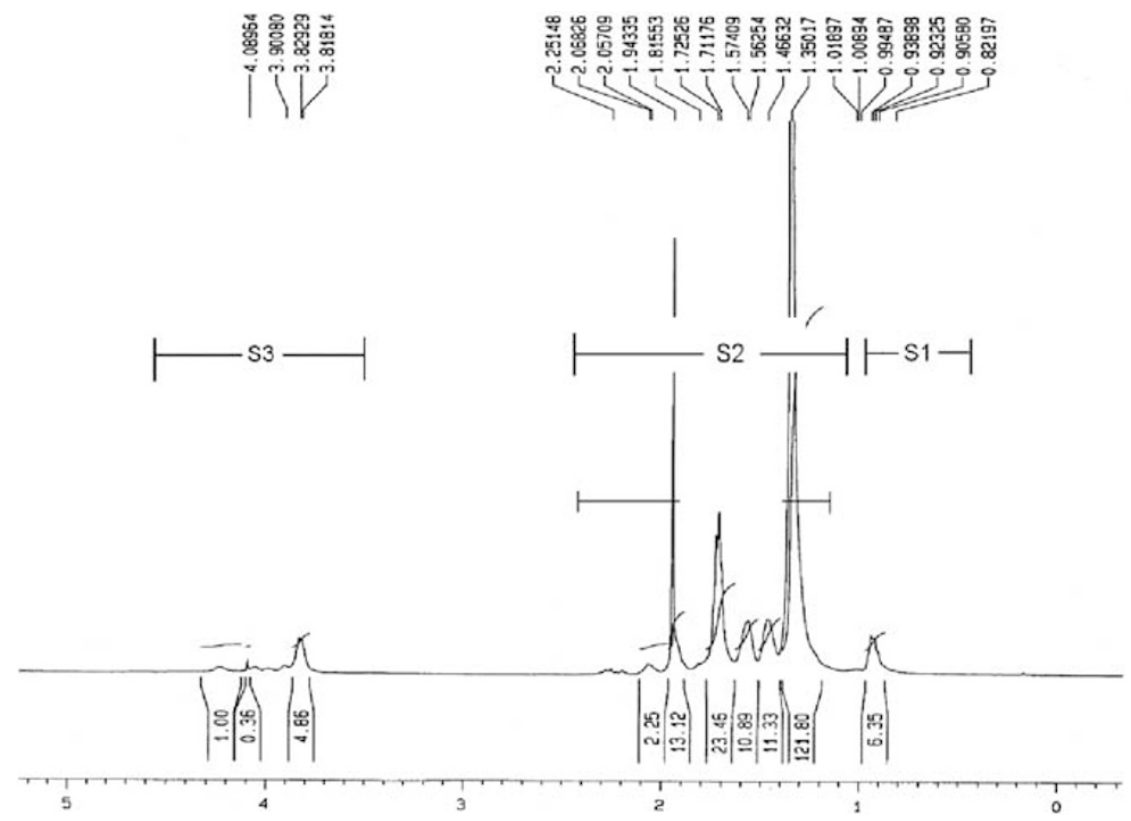

Figure 2 Hydrogen-nuclear magnetic resonance spectra of chlorinated polyethylene containing $13.5 \%$ chlorine. ${ }^{15}$

Table 1 Experimental results for polyethylene chlorination

\begin{tabular}{cccc}
\hline \multicolumn{5}{c}{ Run } & Time (min) & $\begin{array}{c}\text { Chlorine percent obtained by hydrogen-nuclear } \\
\text { magnetic resonance }\end{array}$ & [CHCl] (mol) \\
\hline 1 & 0 & 0 & 0 \\
2 & 50 & 13.5 & 0.2626 \\
3 & 110 & 31.5 & 0.76727 \\
4 & 170 & 41 & 1.1519 \\
5 & 230 & 46.5 & 1.43389 \\
6 & 290 & 49.5 & 1.61215 \\
7 & 340 & 51 & 1.70901 \\
8 & 390 & 52.5 & 1.81164 \\
\hline
\end{tabular}

To identify the sequences of the methylene groups, the notations $\alpha$, $\beta$ and $\gamma$ were used to show the distances from the $\mathrm{CHCl}$ group (one, two and three or more carbon atoms away from chloromethylene, respectively). These sequences can be shown as:

$$
-\mathrm{ClCH}_{2}-\underset{\alpha}{\mathrm{C}} \mathrm{H}_{2}-\underset{\beta}{\mathrm{C}} \mathrm{H}_{2}-\left(\underset{\gamma}{\mathrm{C}} \mathrm{H}_{2}\right)_{n}-\underset{\beta}{\mathrm{C}} \mathrm{H}_{2}-\underset{\alpha}{\mathrm{C}} \mathrm{H}_{2}-\mathrm{CH}_{2} \mathrm{Cl}-
$$

Using the H-NMR spectra, variations of the methylene sequence concentrations $(\alpha, \beta$ and $\gamma)$ can be calculated during the course of the reaction, as shown in Figure 3. As one can see from this figure, the percentage of $\alpha$-methylene sequences does not change considerably up to $40 \%$ chlorination; after that, the percentage of $\alpha$-methylene sequences increases exponentially. The percentage of $\beta$-methylene sequences gradually increased to a maximum value at approximately $40 \%$ chlorination and then decreased at a higher rate beyond this concentration. The percentage of $\gamma$-methylene sequences decreases as the chlorination reaction continues. For a detailed discussion, the reader is referred to Moradi et al. ${ }^{15}$

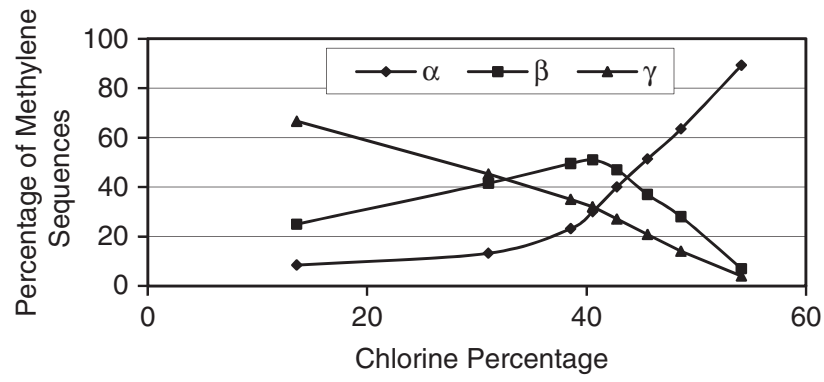

Figure 3 Relative fractions of $\alpha$-, $\beta$ - and $\gamma$-methylene sequences during the reaction. ${ }^{15}$

\section{Verification of reaction kinetics.}

To investigate the reaction kinetics, the variations of the methylene concentration with respect to time are plotted in Figure 4. If Equation (20) holds, the kinetics reaction of chlorination will be first order with respect to the methylene concentration. Based on this hypothesis, variations of the methylene concentration vs time should have an exponential trend. If an exponential function were fitted to these data (Figure 4), the correlation coefficient $\left(R^{2}\right)$ would be 0.9689 . If variations of the methylene concentration with respect to time are analyzed more carefully, it will be observed that the relationship initially exhibits a linear functionality with time, while at the end it varies exponentially with respect to time. Therefore, a line is fitted to the first four data points, and an exponential function is fitted to the second four data points. As can be seen from Figure 4, the correlation coefficients of these fittings are 0.99375 and 0.99821 , respectively. The above functionalities of the methylene concentration with respect to time can be justified as explained below. At the beginning of the chlorination reaction, the concentrations of the chlorine radicals and the methylene groups are high. Therefore, the termination reaction rate $r_{4}$ is dominant, and the reaction rate is given by equation 19 . In all experiments, the chlorine flow rate was selected to be high, and therefore the reaction solution is almost saturated by chlorine radicals. 


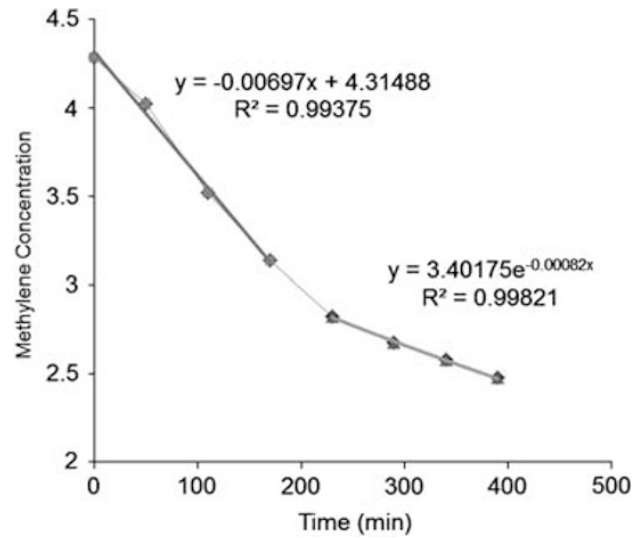

Figure 4 Variation of the methylene concentration vs time during the course of the reaction. A full color version of this figure is available at Polymer Journal online.

This means that in equation 19, the chlorine radical concentration can be considered a constant; therefore, the reaction rate is constant at the beginning of the chlorination reaction. This fact justifies the linear variations of the methylene concentration with respect to time, as shown in Figure 4.

As the reaction proceeds, for chlorination higher than $40 \%$, the concentration of $\beta$-methylene sequences decreases and the concentration of $\gamma$-methylene groups also decreases, but at a higher rate (Figure 3), which results in a lower consumption of chlorine radicals and leads to dominancy of termination reaction rate $r_{6}$. Therefore, at a higher polymer chlorine content (more than $40 \%$ ), the reaction rate is given by equation 20 , which is consistent with the exponential behavior of the methylene concentration variations with respect to time at a higher polymer chlorine percentage. equation 20 can be written as follows:

$$
r=-\frac{\mathrm{d} B}{\mathrm{~d} t}=\frac{K_{2}}{K_{6}^{0.5}}(\varphi I)^{0.5} B=K^{\prime} B
$$

or

$$
B=B_{0} \exp \left(-K^{\prime} t\right)
$$

Using Figure $4, K^{\prime}$ is obtained as given below:

$$
K^{\prime}=0.00082 \mathrm{~min}^{-1}
$$

\section{CONCLUSIONS}

To model the radical chlorination reaction of polyethylene, a kinetics model similar to the one proposed for the photochlorination reaction of tetrachloroethene was used in this work. Photochlorination of polyethylene was conducted in a lab-scale experimental setup, and the results were analyzed by the H-NMR technique. Conversion of methylene units to chloromethylene groups is considered to be the main reaction step, and the concentrations of different methylene sequences $(\alpha, \beta$ and $\gamma)$ are obtained during the course of the reaction.
By plotting the variations of the methylene concentration vs time, the reaction kinetics and type of termination reaction were identified. By analyzing the experimental data, it has been shown that up to $40 \%$ chlorination, the reaction rate is first order with respect to the chlorine gas concentration and zero order with respect to the methylene group concentration. As the reaction continues and the degree of chlorination exceeds $40 \%$, the reaction order changes and becomes zero order with respect to the chlorine gas concentration and first order with respect to the methylene group concentration.

1 Kroschwite, J., March, H. F. \& Gaylord, N. M. Polyethylene Compounds. Encyclopedia of Polymer Science and Technology. 2nd edn, 495-512 (John Wiley and Son's, NY, 1985).

2 Nishimato, W. \& Sinclair, K. B. Chlorinated Polyethylene. Vol. 83, pp 1-70 (Stanford Research Institute (SRI International), Menlo Park, California, 1984).

3 Salamone, J. C. Chlorinated and Chlorosulfonated Polyethylene Polymeric Material Encyclopedia Vol 2, 1235-1262 (CRC Press, Boca Raton, FL, 1996).

4 Ito, N., Okayama, K., Karasuda, T. \& Migagawa, Y. Process for the preparation of chlorinated polyolefins and chlorosulfonated polyolefin. US Patent 5378766 (1995).

5 Nakagawa, T., Narui, M. \& Sakanaka, Y. Method of making chlorosulfonated polyethylene. US Patent 4871815 (1989).

6 Narui, M. Method of chlorination or chlorination and chlorosulfonation. J.P. Patent 63172702 (1988)

7 Ishida, Y. \& Okayama, K. Process for producing chlorinated polyolefin. US Patent 5290879 (1994).

8 Ryan, D. J. Chlorination and chlorosulfonation of polyethylene in mixed solvent. US Patent 4145491 (1979).

9 Bish, C., Brugle, E. G. \& Eniss, R. F. Process for preparation and chlorosulfonation of olefin polymer having low level of residual monoflorobenzene reaction solvent and its chlorinated by products, US Patent H1, 582 (1996)

10 Ishida, Y. \& Okayama, K. Process for producing chlorinated polyethylene in presences of olefin US Patent 5212254 (1993).

11 Blanchard, R. R. Chlorosulfonation of chlorinated polyethylene US Patent 4584351 (1986).

12 Brugel, E. G. Process for chlorination and chlorosulfonation of olefins polymers in suspensions of perflorinated liquids US Patent 5242987 (1993).

13 Schoen, L. A. Process or chlorinating ethylene polymers US Patent 3935181 (1976).

14 Moradi, A. Recycling of Polyethylene using Chlorosulfonation Reaction Ph.D. Thesis. Sharif Univ. Technology, Tehran. Iran, (2005).

15 Moradi, A., Ramazani, S. A. \& Shahrokhi, M. Radical chlorination of polyethylene and molecular structure characterization of reaction products. Polym. J 37, 661-668 (2005).

16 Moradi, A., Ramazani, A. \& Shahrokhi, M. Photochlorination of Polyethylene in Atmospheric Pressure. 10th Appche Conf. (Kitakyushu. Japan, 2004).

17 Moradi, A., Ramazani, A. \& Shahrokhi, M. Radical chlorination of hdpe/ldpe in atmospheric pressure. 6th Iranian Seminar on Polymer Science and Technology Iran (ISPST2003) (2003).

18 Ding, J. S., Sharma, S. H. \& Luss, D. Steady state multiplicity and control of chlorinated of liquid n-decane in an adiabatic continuously stirred tank reactor. Ind. Eng. Chem. Fund. 13, 46-52 (1974).

19 Cramage, M. R. \& Eckert, R. Kinetics of the liquid phase chlorination of n-dodecane. Ind. Eng. Chem. Fund. 14 (1975).

20 Ramag, M. \& Eckert, R. Effect of interphase mass transfer on product selectivity in liquid phase paraffin chlorination. Industrial and engineering chemistry. Proc. Des. Dev. 12 (1973).

21 Ledakowicz, S. \& Miller, J. S. Kinetic of tetrachloroethylene photochlorination. Chem. Eng. Sci. 48, 2443-2451 (1993).

22 Miller, J. S., Nowicki, L. \& Ledakowicz, S. Kinetic of tetrachloroethylene photochlorination in a homogeneous system. Chem. Eng. Tech. 16, 429-432 (1993).

23 Silvershtin, R. M., Bassler, G. C. \& Morile, T. S. Spectrometric Identification of Organic Compounds (John Wiley and Sons, New York, 1991).

24 Pavia, D. L., Lapman, G. M. \& Kriz, G. S. Introduction to Spectroscopy Analyzing (Saunders Company, Philadelphia, 1987).

25 Sadtler, P Standard N.M.R. Spectra. Sadtle Research Laboratories Subsidiary of Block Engineering Vol. 21, 13921M, 26:17063M (Philadelphia, 1976). 